\title{
Chronic Stress and Its Consequences on Subsequent Academic Achievement among Adolescents
}

\author{
Karin Schraml (Corresponding author) \\ Stress Research Institute, Stockholm University \\ SE-106 91 Stockholm, Sweden
}

Tel: 46-737-078-911_E-mail: karin.schraml@stress.su.se

\author{
Aleksander Perski \\ Stress Research Institute, Stockholm University \\ SE-106 91 Stockholm, Sweden
}

Tel: 46-737-078-922Ｅ-mail: aleksander.perski@stress.su.se

\section{Giorgio Grossi}

Stress Research Institute, Stockholm University

SE-106 91 Stockholm, Sweden

Tel: 46-737-078-905Ｅ-mail: giorgio.grossi@stress.su.se

\author{
Irena Makower \\ Manova Cognitive Therapy and Education \\ Kungsgatan 84, SE-112 27 Stockholm, Sweden \\ Tel: 46-708-471-413 E-mail: makower@manova.se
}

$\begin{array}{lc}\text { Received: January 18, } 2012 & \text { Accepted: February 10, } 2012 \quad \text { Published: May 1, } 2012 \\ \text { doi:10.5539/jedp.v2n1p69 } & \text { URL: http://dx.doi.org/10.5539/jedp.v2n1p69 }\end{array}$

This research was supported by the Länsförsäkringar Alliance, Sweden. The opinions expressed are those of the authors and do not reflect a position, policy or endorsement from the Länsförsäkringar Alliance.

\begin{abstract}
Chronic stress has been associated with severe stress-related symptoms not only among adults but also among adolescents. The aim of the study was to investigate if chronic stress has implications for adolescents' academic achievement. 270 high school students answered a questionnaire on stress symptoms on two occasions, at the beginning and at the end of high school. Those who perceived severe stress symptoms at both time points finished high school with significantly worse final grades than those who reported experiencing stress at only one or none of the time points. The risk for chronic stress was increased among adolescents with low global self-esteem, who perceived high demands and reported their self-rated health to be poor and their sleep duration to be insufficient. The results suggest that the early prevention of chronic stress is critical since, if left untreated, it can have serious consequences on young people's future health and career possibilities.
\end{abstract}

Keywords: Chronic stress, Adolescents, Academic achievement

\section{Introduction}

Throughout the course of a lifetime, individuals face a broad spectrum of demands and challenges that require the use of adaptive coping methods, which implies that life is stressful and that stress experiences are thus 
inevitable (Thoreson \& Eagleston, 1983). Stress experiences are therefore here considered to be a mobilization of energy for mastering life's demands and challenges and thereby restoring the disrupted physical balance that stress may bring about.

An energy imbalance can arise when more energy is spent than is gained and if this persists over a long period of time, chronic stress emerges. Persistent energy depletion of this type has been associated with stress symptoms, such as emotional exhaustion, physical fatigue, and cognitive difficulties (Melamed, Kushnir, \& Shirom, 1992; Shirom, 2003). Chronic stress implicates negative consequences on health and well-being (Perski, 2006; Schaufeli \& Enzmann, 1998) and has been associated with a heightened risk for cardiovascular morbidity, diabetes, immunosuppression, depression, anxiety, and exhaustion syndrome (Johnston-Brooks, Lewis, Evans \& Whalen, 1998; Low, Salomon \& Matthews, 2009; Perski, 2006). In Sweden, exhaustion syndrome is among the most common diagnoses qualifying adults for long-term sick leave (National Insurance Board, 2011; Social styrelsen, 2003).

It is not only adults who suffer from the negative consequences of prolonged stress. Within the last 20 years, stress and its associated mental health problems have been increasing dramatically among Swedish adolescents (Hagquist, 2010) and it has become a serious public concern (KVH, 2010; SBU, 2010). A number of national surveys and investigations have confirmed the situation, finding that every third adolescent reported serious stress-related symptoms (Bremberg, 2006; Schraml, Perski, Grossi, \& Simonsson-Sarnecki, 2011; Socialstyrelsen, 2009). Females have been shown to be more vulnerable to stress and its negative implications on health and well-being than males (Basow \& Rubin, 1999; Hagquist, 2009; Schraml et al., 2011).

Since stress-related symptoms emerge over an extended period of time, a fully developed exhaustion syndrome might not be expected to be prevalent among younger populations. However, according to Thoreson and Eagleston (1983), chronic stress has more immediate consequences than the development of a recognizable physical or mental disease. In fact, chronic stress has been associated with greater diastolic blood pressure (Brady \& Matthews, 2006; Low et al., 2009), maladjustment in high school (Kenny, Gallagher, Alvarez-Salvat, \& Silsby, 2002), and depression (Byrne, Davenport, \& Mazanov, 2007; Hankin, Mermelstein, \& Roesch, 2007) among adolescents. Furthermore, it was shown that chronic stress has a negative impact on cognitive functioning throughout a person's lifespan (Marin et al., 2011). While the pernicious consequences of chronic stress on health are recognized and have been well-investigated, research has not focused on the effects that chronic stress may have on other important life domains, such as academic achievement among adolescents.

School issues are a common concern among adolescents and concerns over college admissions, in particular, can bring about a sense of urgency for many (Huan, Lay See, Ang, \& Wan Har, 2008). In Sweden, the completion of high school is necessary in order to get accepted to college. Higher final grades strongly facilitate admission to high ranking tertiary educational programs. Academic achievement influences young people's future opportunities in terms of later educational and occupational attainment. Academic achievement has in fact not only been linked to optimal adolescent functioning but is also considered to be a reliable indicator for future well-being (Schmidt \& Padilla, 2003).

Several studies have investigated the association between striving for high academic achievement and stress. Ollfors and Andersson's (2007) study among Swedish youth showed that the greater the commitment to schoolwork was, the higher the level of perceived stress. Those adolescents who experienced the highest levels of stress also considered the demands placed on them to be far too great. Huan et al. (2008) found that students who rated school-related demands as one of their main sources of stress were also more likely to worry about their studies and feel overwhelmed by their workload. According to Murberg and Bru (2004), worries about school achievement and feeling that schoolwork is too demanding are particularly associated with psychosomatic symptoms. This suggests that pressure to achieve good grades as well as demanding schoolwork may be of importance in predicting psychosomatic symptoms among adolescents. According to Kaplan, Liu and Kaplan (2005), perceived stress not only has consequences on emotional adjustment but also on academic performance among adolescents. After then examining the role of personal academic expectations for academic performance, Kaplan et al. (2005) found that extremely high expectations were counterproductive, especially in a highly stressful school environment. In other words, high academic expectations, which imply high perceived demands, may serve to increase school-related stress and thereby impede academic performance.

Although the relationship between academic stress and achievement has been examined extensively in research, there is little consensus about the nature of these associations. Gustafsson et al. (2010) observed a bidirectional negative relationship between stress and academic achievement. Internalized problems, like stress, anxiety and depressive mood, were associated with negative effects on academic achievement; doing poorly in school, in 
turn, was shown to affect mental health. Other research has failed to predict academic achievement by means of general anxiety (Desiderato \& Koskinen, 1969).

Although the high prevalence of stress-related health problems among adolescents is evident in numerous studies (Bremberg, 2006; KVH, 2010; SBU, 2010; Socialstyrelsen, 2009), to our knowledge, little attention has been paid thus far to the effects that the experiencing of long-term stress symptoms may have on academic achievement.

Because of its negative health consequences, finding effective ways to prevent chronic stress among adolescents is of great concern. In order to begin to achieve this goal, it is important to identify which individuals are at risk. However, with the lack of previous information about the risk factors for chronic stress among adolescents further study has been needed. In regard to stress in general, previous research has identified a number of important risk factors for stress, such as low self-esteem (Baumeister, Campbell, Krueger, \& Vohs, 2003; Hallsten, Josephson \& Torgén, 2005; Rector \& Roger, 1997), low social support, perceived high demands and low control (Karasek \& Theorell, 1990), sleep disturbances and sleep deprivation (Bernet, Merrill, Braithwaite, VanOrden, \& Joiner, 2007; Söderström, Ekstedt, Åkerstedt, Nilsson, \& Axelsson, 2004). Furthermore, low self-rated health (Andreasson Nixon, 2010) and low total life satisfaction (Salmela-Aro \& Tynkkynen, 2010) have been associated with stress experience. Examining the relative roles that these factors may have for chronic stress among adolescent boys and girls was of further interest in the present study.

\subsection{Aim of the Present Study}

Given the above information, the aim of the present study was to examine if high school students who have been persistently perceiving stress over a longer period of time (i.e., two years in the present study), differ significantly with regard to academic achievement from students who experience stress only from time to time periodically or from students who do not perceive any stress symptoms during their time in high school. In addition, the relative importance of risk factors, previously associated with stress, were tested among individuals experiencing chronic stress.

\subsection{Research Questions}

How is subsequent academic achievement affected by previously perceived chronic stress symptoms?

Which factors constitute a heightened risk for chronic stress?

\section{Method}

\subsection{Participants and Procedure}

Data collection took place at two different high ranking high schools after approval by the local ethics review board. Prior to data collection, students and parents were informed in writing about the aims of the study and asked for their consent. Participation was voluntary. The high school students who agreed to participate were asked to silently and individually fill out a questionnaire during a designated school lesson in the presence of a school staff member.

In February 2006, the first data collection took place among 171 high school students at a high school in Stockholm, who answered a questionnaire concerning stress and stress-related variables. Two years later, in February 2008, the same group was asked to answer the questionnaire once again. This time, 119 high school students participated in the data collection, which produced a longitudinal response rate of $70 \%$.

In February 2008, the questionnaire was presented at a second high school, where 285 students volunteered for the first round. In a follow-up of the same students two years later, 176 participated again in the data collection, which produced a longitudinal response rate of $62 \%$.

In order to control for attrition effects, the data from the students who did not participate at time 2 was analyzed. Compared to those who participated on both measurement occasions, no significant differences were found on any of the examined variables.

After excluding incomplete and missing data, the data from 273 participants remained for the subsequent analyses.

\subsection{Measures}

The measures in the study included the Shirom Melamed Burnout Measure (SMBM), which is designed to measure chronic stress according to perceived stress symptoms. The SMBM contains 22 items (graded 1-7) that measure different facets of chronic stress by focusing on the depletion of an individual's energetic resources (Melamed et al., 1992). The respondents rate how much physical, emotional and psychological stress symptoms 
they experience (Shirom \& Melamed, 2006). High scores indicate an intense experiencing of stress symptoms. In this study, as in previous studies, a rating of 4 or above was considered to be indicative of serious stress symptoms (Grossi, Perski, Evengård, Blomkvist, \& Orth-Gomér, 2003). The Cronbach's $\alpha$ coefficient was 0.93 at time 1 and 0.94 at time 2 .

The outcome variable of most interest was academic achievement. The students' final grades, which are based on their total academic performance throughout high school served as indicators for academic achievement. In the investigated sample, the final grades varied from 6.20 to 20 points $(M=16.80, S D=2.356)$ with higher values indicating better grades. Moreover, the individual high school entrance grades were available for 112 students.

To measure global self-esteem, Rosenberg's self-esteem scale (RSE-scale) was utilized at time 1 (Rosenberg, 1972; Vispoel, Boo, \& Bleiler, 2001). Global self-assessment was measured using 10 generally formulated items (graded 1-4) (e.g., Sometimes I feel rather worthless; There is nothing I could be proud of; In general, I am quite content with myself). High scores indicate high global self-esteem, which reflects a respondent's overall feeling of being "good enough." The Cronbach's $\alpha$ coefficient was 0.90 .

The Performance-Based Self-esteem scale (PBS-scale) (Hallsten et al., 2005) consists of four items (graded 1-4), and was used to assess to what degree the respondents' self-esteem is based on performance and success (I think I sometimes try to prove my worth by being competent; My self-esteem is far too dependent on my daily achievements; At times, I have to be better than others to feel good enough myself; Occasionally I feel obsessed to accomplish something of value). In this study, high scores indicate high performance-based self-esteem. The Cronbach's $\alpha$ coefficient was 0.81 .

Perceived demands, control, and social support, which are important stress-related variables according to Karasek and Theorell (1990), were measured by 17 items (graded 1-4). Demands were measured using an index of five items concerning qualitative and quantitative demands, such as time pressure and conflicting demands (e.g., Do you feel life is too demanding?; Are there many conflicting demands in your life?). High scores indicated that the perceived demands were high. The Cronbach's $\alpha$ coefficient was 0.84 . The control index included six items to capture such areas as skill discretion and authority over decisions (e.g., Can you make decisions about your life on your own?; I constantly need to learn new things in order to deal with my life). Low scores indicated a lack of perceived control. The Cronbach's $\alpha$ coefficient was 0.30. Social support was measured by an index of 6 items and focuses on the social climate in school (e.g., I get along well with my schoolmates; There is a good sense of togetherness in my class) (Bernin \& Theorell, 2001). High scores indicate that social support is high. The Cronbach's $\alpha$ coefficient was 0.76 .

Sleep disturbances were examined by an eight question index (graded 1-5) taken from the Karolinska sleep questionnaire (KSQ) (e.g., I have difficulties falling asleep; I do not feel well-rested when I wake up in the morning; I experience disturbed sleep) (Kecklund \& Åkerstedt, 1992). The Cronbach's $\alpha$ coefficient was 0.71.

Moreover, three generally formulated questions from the Stress Research Institute's stress screening questionnaire were included (Schraml et al., 2011). The first one concerned perceived sleep duration (Do you feel like you sleep long enough?) and was graded from 1 (yes, definitely long enough) to 5 (no, far from long enough). The second question was graded from 1 (very satisfied) to 5 (very unsatisfied) and regarded total life satisfaction (In general, how satisfied are you with your current life situation?). The last question (graded from $1=$ very good to $5=$ bad) concerned self-rated health (How would you say your general health has been during the past year?).

\subsection{Data Analysis}

According to their responses on the SMBM items at time 1 and time 2, and using the cut-off point of 4 or more, the students were categorized into three different stress groups: a no-stress group, a transitory stress group, and a chronic stress group.

Because of the low reliability (Cronbach's $\alpha=0.30$ ) among the items measuring perceived control, these items were excluded from further analyses.

In a first step, the data was explored by means of descriptive statistics and a multivariate analysis of variance was conducted. In a second step, to answer the research questions, an analysis of variance and a logistic regression analysis were conducted. The statistical analyses were carried out using the Statistical Package for Social Sciences (SPSS) version 17.0 for Windows. 


\section{Results}

\subsection{Descriptive Statistics}

Among all of the investigated high school students, 173 (63\%), 106 boys and 67 girls, did not feel stressed, neither at the beginning of high school nor two years later and were placed in the no-stress group.

In the transitory stress group were 59 students $(22 \%), 20$ boys and 39 girls, who reported experiencing a high degree of stress symptoms temporarily, either at the beginning or at the end of their time in high school.

Finally, the chronic stress group, consisting of students who reported high levels of stress related symptoms both at the beginning and at the end of high school, was made up of 41 students (15\%), 10 boys and 31 girls.

Since the individual high school entrance grades for 112 students were available, a simple one-way ANOVA was carried out in order to investigate if there were initial differences between the stress groups regarding academic achievement. The results showed that there were no initial differences between the three stress groups in terms of the students' entrance grades ( $\mathrm{F} 2,109=1.001, \mathrm{p}=0.371, \mathrm{~ns})$.

The data was then tested to see if there were any differences between the three stress groups with regard to all of the other investigated variables. Since there was a significant imbalance in sex distribution across the three stress groups, with greater numbers of males in the no stress group and greater numbers of females in the transitory and chronic stress groups, gender was entered in the analysis as a second fixed factor. Thus, a 2 (gender) x 3 (stress group) MANOVA was conducted. The MANOVA yielded a significant multivariate effect of stress group (Wilks' lambda $=.628, \mathrm{~F} 16,496=8.122, \mathrm{p}<0.001$, partial $\eta^{2}=.208$ ) and gender (Wilks' lambda $=.819, \mathrm{~F} 8,248=6.855$, $\mathrm{p}<0.001$, partial $\eta^{2}=.181$ ). No significant multivariate interaction effects were found, Wilks' lambda $=.905$; F16,496 $=1.589$, ns. Consequently, univariate analyses for between-group differences among the three stress groups and among gender were conducted (see table 1).

\section{Insert Table 1 Here}

There were significant differences between the three stress groups for all of the investigated variables. For the three stress groups, post hoc analyses (Scheffé) of least significant differences were subsequently performed on all pairwise comparisons. All three groups were significantly different from one another in respect to global self-esteem, demands, sleep difficulties, perceived sleep duration, and self-rated health. While the no-stress group reported the highest levels of global self-esteem and self-rated health, as well as less sleeping difficulties and demands, and an adequate perceived duration of sleep, the chronic stress group reported the lowest levels of global self-esteem and self-rated health. The chronically stressed students also perceived their duration of sleep to be too short, had the most sleeping difficulties, and perceived the highest levels of demands. The temporary stress group reported levels in between the other two groups for the mentioned variables. Regarding performance-based self-esteem and total life satisfaction, the no-stress group differed significantly from the other two groups; they reported lower levels of performance-based self-esteem and greater life satisfaction. Compared to the other two groups, the chronic stress group perceived significantly less social support.

Significant main effects for gender were found with regard to self-esteem, indicating that the females had significantly worse global self-esteem. They further reported higher demands and poorer self-rated health than males. The males, on the other hand, reported that their sleep was more insufficient as compared to the females.

\subsection{Does Chronically Experienced Stress Have any Consequences on Subsequent Academic Achievement?}

To address the question of whether chronically experienced stress symptoms have any consequences on subsequent academic achievement, an ANOVA was conducted. Academic achievement was treated as the dependent variable. Group membership according to levels of experienced stress symptoms and gender constituted the independent variables. The result of the analysis is presented in table 2 .

Insert Table 2 Here

According to the results of the ANOVA, comparing the final grades of the different stress groups showed significant differences $\left(\mathrm{F} 2,266=5.605, \mathrm{p}=0.004\right.$, partial $\left.\eta^{2}=0.040\right)$. It was revealed that the chronic stress group achieved significantly worse grades than the other two groups, which did not differ significantly from each other. Furthermore, there was neither a main effect for gender $(\mathrm{F} 1,266=3.333 ; \mathrm{p}=0.069$, ns) nor any interaction effect $(\mathrm{F} 1,266=1.159 ; \mathrm{p}=0.315, \mathrm{~ns})$.

\subsection{What Are the Factors that Predict a Heightened Risk for Chronic Stress?}

To investigate the relative importance of the investigated variables for predicting membership in either of the extreme groups, that is, the no-stress and chronic stress groups, a logistic regression analysis was conducted 
(table 3). Before being entered into the analysis, all predictor variables were z-standardized. The dependent variable was membership in either the no-stress or chronic stress group.

\section{Insert Table 3 Here}

The inferential Hosmer \& Lemeshow goodness-of-fit test yielded a $\chi^{2}(8)$ of 3.348 and was insignificant $(\mathrm{p}>.05)$, suggesting that the model fitted the data well. The $\mathrm{R}^{2}$, as defined by Nagelkerke, was .673 . Even though the discrimination between chronically stressed and non-stressed individuals by means of the estimated model was not perfect $(90.7 \%)$, it was better than chance $(81 \%)$. The present results indicate that perceived high demands, low global self-esteem, perceived short sleep duration, and poor self-rated health were relevant indicators for an increased risk of chronic stress during high school.

\section{Discussion}

Adolescence is a stressful period in life (Arnett, 1999). The negative consequences of stress on the health and well-being of young people are well-known at this point and of public concern $(\mathrm{KVH}, 2010$; SBU, 2010; Schraml et al., 2011). It is not only the consequences on health that are a problem as there are also other implications for important life domains which can significantly impact a young person's future life, such as academic performance. The present study's aim to investigate the consequences that various degrees of stress experience can have on academics sheds some light on this important area.

According to our results, the students who experienced stress chronically showed significantly worse final grades at the end of high school than the students who perceived no stress or temporary stress. The academic achievement of students who did not experience any stress symptoms during their time in high school as well as those who experienced stress symptoms under a shorter period of time was not influenced negatively. It seems as if these students were easily able to handle the academic challenges they met in school. Even though the difference found between the groups was small, as indicated by a small effect size, it should not be neglected. Indeed, if chronic stress had a significant effect on academic achievement in this rather homogenous group of highly ambitious adolescents, one could expect even stronger effects in other populations of less ambitious high school students.

For the chronically stressed students, it is, in fact a most alarming result, especially when considering that we live in a highly competitive society, which reinforces the ambitious striving for success. Achievement is especially relevant in an educational setting, like high school, where it can make or break a student's future career prospects (Schmidt \& Padilla, 2003). Receiving low final grades will preclude chronically stressed students from gaining acceptance into a high-ranked tertiary line of education. The results of the present study support Kaplan et al.'s (2005) finding of a negative relationship between perceived stress and performance.

Fortunately, the no-stress group was the largest $(63 \%)$, which suggests that the majority of high school students do not experience severe stress symptoms. However, taken together, 97 adolescents $(39 \%)$ experienced high levels of stress-related symptoms at least once during their time in high school.

When it comes to gender differences, the results of the present study support the findings of earlier investigations (Bremberg, 2006; Hagquist, 2009; Schraml et al., 2011). Every other girl reported having experienced severe stress symptoms at least once in high school compared to every fifth boy. Girls not only constituted the majority of the chronically stressed group, they also showed significantly worse global self-esteem and perceived higher demands compared to males. They also had poorerself-rated health. The boys, on the other hand, especially those in the chronically stressed group, reported that they did not sleep long enough to a greater extent than the girls.

A central issue seems to be the cognitive appraisal of the situation and individual predisposition/vulnerability for the development of chronic stress. Although all students on the surface objectively face the same school situation, essential school requirements and demands, some are at risk for developing chronic stress symptoms, others are not. In the present study, the likelihood of experiencing chronic stress symptoms during high school was found to be positively related to having experienced high demands at the beginning of high school. Furthermore, having a low level of global self-esteem at the beginning of high school was a significant predictor for chronic stress. Students who perceived that they did not sleep sufficiently during school nights were at greater risk of experiencing prolonged stress symptoms. Finally, poor self-rated health was also found to have a significant impact on the risk for developing chronic stress problems. To further examine individual differences is a task for future research.

Considering the results of the present study, the development of specific interventions for highly stressed adolescents is desirable. Among other things, such interventions should focus on strengthening the adolescents' global self-esteem by helping them find ways to maintain their sense of self-worth even when difficulties arise in 
life (Baumeister et al., 2003; Rosenberg, 1972). Developing young people's capacity to be flexible, when meeting demands, is a key part of this process. This could be provided by training in cognitive reappraisal/reevaluation. Furthermore, a mindfulness approach might be of help by training students to focus on the present moment and to envision situations objectively, which should help them see future events and challenges, like academic exams in a more neutral/positive light rather than as potential disasters and catastrophes. The results of a study on the positive associations between mindfulness and performance among young adults support this approach (Shao \& Skarlicki, 2009). Another important ingredient for preventing chronic stress could be to increase their awareness of the importance of sleep and recovery (Söderström et al., 2004). This would involve learning how to recover appropriately and how to counteract the causes of poor sleep, in terms of both quality and duration (e.g., having too many things to do, not allowing enough time for recovery, problems falling asleep). Finally, young people should be made aware of and encouraged to adopt the kind of behaviors that promote health - for doing so could lead to more positive perceptions of their health and total life situation.

\subsection{Methodological Considerations}

Several limitations may have influenced the results of the present study. Firstly, all instruments measuring stress and stress-related variables were based on self-report questionnaires. Secondly, a number of potentially relevant variables fell outside the scope of our investigation, such as stressful life events, physical illness, cognitive deficits, and family-related issues, which could have had some influence on the present results. Thirdly, the study does not contain any follow-up measures after the completion of high school, which could provide useful information and probably a more reliable prognosis for the students' future in terms of their risk for stress-related health problems. Fourthly, our sample was drawn from only one geographic area, Stockholm, and thus represents a limited range of community and school environments. Moreover, since our investigation only involved highly ambitious students from two high ranked high schools, further investigations would be needed among adolescents from less elitist high schools in order to draw conclusions for all high school students. Finally, it would have been of great value to have had access to the exact entrance grades for all participating students, rather than relying on those of 112 of the participating students. However, it is safe to assume that the rest of the students had at least sufficiently good grades from primary school since they had met the requirements needed for entering high school.

\section{Conclusions}

Chronic stress has more immediate consequences on adolescents in addition to the negative long-term implications it can have on health and well-being. Because of its implications on academic achievement, it can have significant negative repercussions on a young person's future chances of being accepted into a quality line of education.

Adolescents who reported low global self-esteem, high demands, sleep deprivation, or poor health showed a higher risk for developing chronic stress and poor academic achievement.

The results of the present study make a contribution to research on adolescent health and education. The study combines longitudinal self-reported data and objective school information. Thereby, it offers a more concrete understanding of the negative consequences of chronic stress on academic achievement and thus provides a richer context for the development of effective stress intervention strategies in an educational setting.

\section{References}

Andreasson Nixon, A. (2010). Self-rated health.Biobehavioral determinants with focus on inflammatory factors. Thesis for doctoral degree, Karolinska Institute.

Arnett, J. J. (1999). Adolescent storm and stress, reconsidered. American Psychologist, 54 (5), 317-326.

Basow, S. A., \& Rubin, L. R. (1999). Gender influences on adolescent development. In N. G. Johnson, M. C. Roberts \& J. P. Worell (Eds.), Beyond appearance: A new look at adolescent girls (pp. 25-52). Washington, DC: American Psychological Association.

Baumeister, R. F., Campbell, J. D., Krueger, J. I., \& Vohs, K. D. (2003). Does high self-esteem cause better performance, interpersonal success, happiness, or healthier lifestyles? Psychological science in the public interest, 4 (1), 1-44.

Bernert, R., Merrill, K., Braithwaite, S., VanOrden, K., \& Joiner, T. (2007). Family life stress and insomnia symptoms in a prospective evaluation of young adults. Journal of Family Psychology, 21(1), 58-66. http://dx.doi.org/10.1037/0893-3200.21.1.58 
Bernin, P., \& Theorell, T. (2001). Demand-control-support among female and male managers in eight Swedish companies.Stress and Health, 17, 231-243.

Brady, S. S., \& Matthews, K. A. (2006). Chronic Stress Influences Ambulatory Blood Pressure in Adolescents. Annals of Behavioral Medicine, 31 (1), 80-88. http://dx.doi.org/10.1207/s15324796abm3101_12

Bremberg, S. (2006). Ungdomar, stress och psykisk ohälsa - Analyser och förslag till åtgärder. (Youngsters, stress and mental health - Analysis and proposals for action) Stockholm: Socialdepartementet, SOU 2006:77. [Online] Available: http://www.regeringen.se/sb/d/108/a/67472

Byrne, D. G., Davenport, S. C., \& Mazanov, J. (2007). Profiles of adolescent stress: The development of the adolescent stress questionnaire (ASQ). Journal of Adolescence, 30, 393-416. http://dx.doi.org/10.1016/j.adolescence.2006.04.004

Desiderato, O., \& Koskinen, P. (1969). Anxiety, Study Habits, and Academic Achievement. Journal of Counseling Psychology, 16 (2), 162-165. http://dx.doi.org/10.1037/h0027213

Grossi, G., Perski, A., Evengård, B., Blomkvist, V., \& Orth-Gomér, K. (2003). Physiological correlates of burnout among women. Journal of Psychosomatic Research, 55, 309-316. [Online] Available: http://www.ncbi.nlm.nih.gov/pubmed/14507541

Gustafsson, J.-E., Allodi, M., Alin.-Åkerman, B., Eriksson, C., Eriksson, L. Fischbein, S., Granlund, M., Gustafsson, P., Ljungdahl, S., Ogden, T., \& Persson, R. S. (2010). School, Learning and Mental Health. A systematic review. Health committee, The Royal Swedish Academy of Sciences. [Online] Available: http://www.kva.se/Documents/Vetenskap_samhallet/Halsa/Utskottet/kunskapsoversikt2_halsa_eng_2010.pdf

Hagquist, C. (2009). Psychosomatic health problems among adolescents in Sweden - are the time trends gender related? European Journal of Public Health, 19 (3), 331-336. http://dx.doi.org/10.1093/eurpub/ckp031

Hagquist, C. (2010). Discrepant Trends in Mental Health Complaints among Younger and Older Adolescents in Sweden: An Analysis of WHO Data 1985-2005. Journal of Adolescent Health, 46, 258-264. http://dx.doi.org/10.1016/j.jadohealth.2009.07.003

Hallsten, L., Josephson, M., \& Torgén, M. (2005). Performance-based self-esteem: A driving force in burnout processes and its assessment. Arbete och Hälsa. Arbetslivsinstitutet (Nr.2005:4). [Online] Avaiable: http://gupea.ub.gu.se/bitstream/2077/4355/1/ah2005_04.pdf

Hankin, B. L., Mermelstein, R., \& Roesch, L. (2007). Sex differences in adoelscent depression: Stress exposure and reactivity models. Child Development, 78 (1), 279-295. http://dx.doi.org/10.1111/j.1467-8624.2007.00997.x

Huan, V. S., Lay See, Y., Ang, R. P., \& Wan Har, C. (2008). The impact of adolescent concerns on their academic stress.Educational Review, 60 (2), 169-178. http://dx.doi.org/10.1080/00131910801934045

Johnston-Brooks, C. H., Lewis, M. A., Evans, G. W., \& Whalen, C. K. (1998). Chronic Stress and Illness in Children: The Role of Allostatic Load. Psychosomatic Medicine, 60, 597-603.

Karasek, R., \& Theorell, T. (1990). Healthy work: stress, productivity, and the reconstruction of working life. New York, NY: Basic Books.

Kaplan, D. S., Liu, R. X., \& Kaplan, H. B. (2005). School related stress in early adolescence and academic performance three years later: the conditional influence of self-expectations. Social Psychology of Education, 8, 3-17.

Kecklund, G., \& Åkerstedt, T. (1992). The psychometric properties of the Karolinska Sleep Questionnaire. Journal of Sleep Research, 1 (suppl. 1), 113.

Kenny, M. E., Gallagher, L. A., Alvarez-Salvat, R., \& Silsby, J. (2002). Sources of Support and Psychosocial Distress among academically successful inner-city youth. Adolescence, 37 (145), 161-182. [Online] Available: http://www.ncbi.nlm.nih.gov/pubmed/12003288

KVH (Kungliga vetenskapsakademiens hälsoutskott) (2010). Barns och ungdomars psykiska hälsa i Sverige. En systematisk litteraturöversikt med tonvikt på förändring över tid. Research report. [Online] Available: http://kva.episerverhotell.net/sv/

Low, C. A., Salomon, K., \& Matthews, K. A. (2009). Chronic life stress, cardiovascular reactivity, and subclinical cardiovascular disease in adolescents. Psychosomatic Medicine, 71 (9), 927-931. http://dx.doi.org/10.1097/PSY.0b013e3181ba18ed

Marin, M. F., Lord, C., Andrews, J., Juster, R. P., Sindi, S., Arsenault-Lapierre, G., Fiocco, A. J., \& Lupien, S. J. 
(2011). Chronic stress, cognitive functioning and mental health. Neurobiology of Learning and Memory, Article in press. http://dx.doi.org/10.1016/j.nlm.2011.02.016

Melamed, S., Kushnir, T., \& Shirom, A. (1992). Burnout and Risk Factors for Cardiovascular Diseases.Behavioral medicine.An interdisciplinary journal of research and practice, 18, 53-60.

Murberg, T. A., \& Bru, E. (2004). School-related Stress and psychosomatic Symptoms among Norwegian Adolescents. School Psychology International, 25 (3), 317-332. http://dx.doi.org/10.1177/0143034304046904

National Insurance Board (2011). REHSAM - forskning om arbetsrehabilitering. [Online] Available: http://www.forsakringskassan.sev

Ollfors, M., \& Andersson, S. I. (2007). Ability of stress, sense of control, and self-theories to predict Swedish high school students' final grades. Educational Research and Evaluation, 13 (2), 143-169.

Perski, A. (2006). Ur balans. Bonnier Fakta.

Rector, N. A., \& Roger, D. (1997). The stress buffering effects of self-esteem. Personality and Individual Differences, 23(5), 799-808.

Rosenberg, M. (1972). Society and the adolescent self-image.Princeton, NJ University Press.

Salmela-Aro, K., \& Tynkkynen, L. (2010). Trajectories of Life Satisfaction Across the Transition to Post-Compulsory Education: Do Adolescents Follow Different Pathways? Journal of Youth and Adolescence, 39, 870-881. http://dx.doi.org/10.1007/s10964-009-9464-2

SBU (2010). Methods to prevent mental ill-health in children.A systematic review. Report 202. Swedish Council on Health Technology Assessment. [Online] Available: http://www.sbu.se/upload/Publikationer/Content0/1/Program_forebygga_psykisk_ohalsa_hos_barn.pdf

Schaufeli, W., \& Enzmann, D. (1998). The burnout companion to study and practice: A critical analysis. Taylor \& Francis.

Schmidt, J. A., \& Padilla, B. (2003). Self-Esteem and Family-Challenge: An Intervention of their Effects on Achievement. Journal of Youth and Adolescence, 32 (1), 37-46.

Schraml, K., Perski, A., Grossi, G., \& Simonsson-Sarnecki, M. (2011). Stress symptoms among adolescents: The role of subjective psychosocial conditions, lifestyle and self-esteem. Journal of Adolescence, 34 (5), 987-996. http://dx.doi.org/10.1016/j.adolescence.2010.11.010

Shao, R., \& Skarlicki, D. P. (2009). The Role of Mindfulness in Predicting Individual Performance. Canadian Journal of Behavioral Science, 41 (4), 195-201. http://dx.doi.org/10.1037/a0015166

Shirom, A. (2003). Job-related burn out. In J.C. Quick \& L.E. Tetrick (Eds.), Handbook of occupational health psychology (pp. 245-265). Washington, DC: American Psychological Association.

Shirom, A., \& Melamed, S. (2006). A comparison of the Construct Validity of Two Burnout Measures in Two Groups of Professionals. International Journal of Stress Management, 13 (2), 176-200. http://dx.doi.org/10.1037/1072-5245.13.2.176

Socialstyrelsen (2003). Utmattningssyndrom. Stressrelaterad psykisk ohälsa.(Exhaustionsyndrome. Stress-related mental illness.)Report. [Online] Available: http://www.socialstyrelsen.se/publikationer2003/2003-123-18.

Socialstyrelsen (2009). Folkhälsorapport. (Public Health report). [Online] Available: http://www.socialstyrelsen.se/publikationer2009/2009-126-71

Söderström, M., Ekstedt, M., Åkerstedt, T., Nilsson, J., \& Axelsson, J. (2004). Sleep and Sleepiness in Young Individuals with High Burnout Scores. Sleep: Journal of Sleep and Sleep Disorders Research, 27 (7), 1369-1377. [Online] Available: http://www.ncbi.nlm.nih.gov/pubmed/15586790

Thoreson, C. E., \& Eagleston, J. R. (1983). Chronic stress in children adolescents. Theory into Practice, 22 (1), 48-56.

Vispoel, W. P., Boo, J., \& Bleiler, T. (2001). Computerized and paper-and-pencil versions of the Rosenberg self-esteem scale: a comparison of psychometric features and respondent preferences. Educational and Psychological Measurement, 61 (3), 461-474. Sage Publications, Inc. 
Table 1. Between-group differences for stress-related variables and gender

\begin{tabular}{|c|c|c|c|c|c|c|}
\hline & \multirow[t]{2}{*}{ No-stress } & \multirow{2}{*}{$\begin{array}{c}\text { Transitory } \\
\text { stress }\end{array}$} & \multirow{2}{*}{$\begin{array}{c}\text { Chronic } \\
\text { stress }\end{array}$} & \multicolumn{2}{|c|}{$F$ ratios $\left(\eta^{2}\right)^{\wedge}$} \\
\hline & & & & & Stress groups & Gender \\
\hline & & M (S.D.) & M (S.D.) & M (S.D.) & & \\
\hline \multirow{2}{*}{$\begin{array}{l}\text { Global } \\
\text { self-esteem }\end{array}$} & q & $3.25(.572)$ & $3.02(.583)$ & $2.55(.559)$ & \multirow{2}{*}{$\begin{array}{c}19.40^{* * *} \\
(.132)\end{array}$} & \multirow{2}{*}{$\begin{array}{c}24.55^{* * *} \\
(.088)\end{array}$} \\
\hline & $0^{\lambda}$ & $3.58(.383)$ & $3.38(.444)$ & $3.08(.611)$ & & \\
\hline \multirow{2}{*}{$\begin{array}{l}\mathrm{Pb} \\
\text { self-esteem }\end{array}$} & $q$ & $3.12(.939)$ & $3.39(.904)$ & $3.58(.921)$ & \multirow{2}{*}{$\begin{array}{l}4.52 * \\
(.034)\end{array}$} & \multirow[t]{2}{*}{1.40} \\
\hline & $\hat{0}^{\lambda}$ & $2.88(1.015)$ & $3.38(1.162)$ & $3.25(.905)$ & & \\
\hline \multirow[t]{2}{*}{ Demands } & q & $2.84(.562)$ & $3.13(.426)$ & $3.55(.315)$ & \multirow{2}{*}{$\begin{array}{c}26.34 * * * \\
(.171)\end{array}$} & \multirow{2}{*}{$\begin{array}{c}14.30 * * * \\
(.053)\end{array}$} \\
\hline & $0^{\pi}$ & $2.47(.584)$ & $2.94(.511)$ & $3.13(.514)$ & & \\
\hline \multirow[t]{2}{*}{ Social support } & q & $3.43(.350)$ & $3.28(.474)$ & $3.09(.536)$ & \multirow{2}{*}{$\begin{array}{l}8.28 * * \\
(.061)\end{array}$} & \multirow[t]{2}{*}{.14} \\
\hline & $0^{\pi}$ & $3.45(.389)$ & $3.28(.441)$ & $3.15(.541)$ & & \\
\hline \multirow{2}{*}{$\begin{array}{l}\text { Sleep } \\
\text { disturbances }\end{array}$} & q & $4.19(.651)$ & $3.88(.683)$ & $3.35(.789)$ & \multirow{2}{*}{$\begin{array}{c}24.72 * * * \\
(.162)\end{array}$} & \multirow[t]{2}{*}{1.60} \\
\hline & $\pi$ & $4.44(.655)$ & $3.84(.746)$ & $3.56(.476)$ & & \\
\hline \multirow[t]{2}{*}{ Sleep duration } & q & $3.42(.801)$ & $3.03(.866)$ & $2.62(.942)$ & \multirow{2}{*}{$\begin{array}{c}37.37 * * * \\
(.227)\end{array}$} & \multirow{2}{*}{$\begin{array}{l}5.16^{*} \\
(.020)\end{array}$} \\
\hline & o & $3.61(.855)$ & $3.00(1.106)$ & $1.50(.527)$ & & \\
\hline \multirow{2}{*}{$\begin{array}{l}\text { Life } \\
\text { satisfaction }\end{array}$} & q & $4.10(.741)$ & $3.70(.702)$ & $3.31(.930)$ & \multirow{2}{*}{$\begin{array}{c}12.06^{* * *} \\
(.086)\end{array}$} & \multirow[t]{2}{*}{2.91} \\
\hline & $0^{\pi}$ & $4.21(.704)$ & $3.74(.872)$ & $3.80(.789)$ & & \\
\hline \multirow{2}{*}{$\begin{array}{l}\text { Self-rated } \\
\text { health }\end{array}$} & q & $3.94(.776)$ & $3.49(.870)$ & $2.86(.833)$ & \multirow{2}{*}{$\begin{array}{c}20.28 * * * \\
(.137)\end{array}$} & \multirow{2}{*}{$\begin{array}{c}14.57 * * * \\
(.054)\end{array}$} \\
\hline & $\hat{0}$ & $4.28(.686)$ & $3.95(.911)$ & $3.50(.707)$ & & \\
\hline
\end{tabular}

Notes. $q=$ females; $\hat{\delta}=$ males. $\mathrm{Pb}=$ Performance based $* \mathrm{p}<.05 .{ }^{*} \mathrm{p}<.01 .{ }^{* * *} \mathrm{p}<.001 . \wedge$ For all significant differences the effect size (partial $\eta^{2}$ ) is provided in parentheses beneath the $F$ ratio. $\mathrm{N}=261$, after list wise deletion of incomplete data.

Table 2. Descriptive statistics for final grades in each stress group

\begin{tabular}{|l|c|c|c|c|}
\hline \multicolumn{2}{|c|}{} & No-stress & Transitory stress & Chronic stress \\
\cline { 3 - 5 } \multicolumn{2}{|c|}{} & M (S.D.) & M (S.D.) & M (S.D.) \\
\hline Final grades & + & $17.40(1.639)$ & $17.58(1.732)$ & $15.55(3.416)$ \\
\hline & $\hat{y}$ & $16.80(2.360)$ & $16.11(2.275)$ & $15.59(3.195)$ \\
\hline
\end{tabular}

Notes..$=$ females; $\hat{\delta}=$ males. ${ }^{*} \mathrm{p}<.05 .{ }^{* *} \mathrm{p}<.01 .{ }^{* * *} \mathrm{p}<.001 . \mathrm{N}=272$, after list wise deletion of incomplete data. 
Table 3.Prediction of group membership (chronic or no-stress group) by means of a logistic regression analysis

\begin{tabular}{|l|c|c|c|c|c|c|}
\hline & B & S.E. & \multicolumn{2}{|c|}{ Sig. } & Exp (B) & \multicolumn{2}{|c|}{$95 \%$ C.I.for EXP(B) } \\
\cline { 4 - 7 } & & & & & Lower & Upper \\
\hline Global self-esteem & -.927 & .327 & .005 & .396 & .208 & .751 \\
\hline Pb self-esteem & -.176 & .346 & .610 & .838 & .426 & 1.651 \\
\hline Demands & 1.181 & .391 & .003 & 3.257 & 1.513 & 7.011 \\
\hline Social support & -.044 & .296 & .882 & .957 & .535 & 1.711 \\
\hline Sleep difficulties & -.073 & .328 & .825 & .930 & .489 & 1.768 \\
\hline Sleep duration & -1.237 & .322 & .000 & .290 & .154 & .546 \\
\hline Life satisfaction & .092 & .320 & .775 & 1.096 & .585 & 2.054 \\
\hline Self-rated health & -.955 & .337 & .005 & .385 & .199 & .746 \\
\hline Constant & -3.194 & .509 & .000 & .041 & & \\
\hline
\end{tabular}

Note. $\mathrm{df}=1 ; \mathrm{Pb}=$ Performance-based. 